\title{
Practical Course Teaching Method Reform and Research
}

\section{Li Qiao ${ }^{1}$, Haibo Wei ${ }^{2}$ and Guangjun $\mathrm{Ma}^{1}$}

${ }^{1}$ Liaoning Vocational College of Equipment and Manufacturing, Shenyang 110161, China;

${ }^{2}$ Liaoning Radio and TV University, Shenyang 110003, China.

\section{9 @qq.com}

\begin{abstract}
Single-chip microcomputer and interface technology is a practical stronger course, students are required to not only have a solid theoretical foundation, at the same time, students are required to have stronger practical ability and innovative thinking. In order to improve students ability and understanding of the single chip microcomputer, through years of single chip microcomputer analysis summarized the problems in the teaching process, this paper puts forward the theoretical knowledge in the teaching way of introducing project teaching, in the experimental part of the introduction of virtual experiment based on Proteus and Keil technology, and gradually applied in the teaching practice, the performance appraisal and competition ability has obtained certain teaching effect.
\end{abstract}

Keywords: Practicality; Single-Chip microcomputer and interface technology; The teaching reform; Project teaching; Virtual experiment

\section{实践性单片机课程教学方法改革及研究}

\author{
乔莉 $1^{1} ，$ 魏海波 $2^{2} ，$ 马广君 $1^{1}$ \\ (1. 辽宁装备制造职业技术学院信息工程学院, 辽宁省 沈阳市 110000 ; \\ 2.辽宁广播电视大学, 辽宁省 沈阳市 110000)
}

摘要: 单片机与接口技术是一门实践性较强的课程, 不仅要求学生具有扎实的理论基础, 同时要求学生具有较强的动手 能力和创新思维。为提高学生对单片机的理解能力、动手能力, 通过对多年单片机教学过程中遇到的问题进行分析总结, 本 文提出了在理论知识讲授中引入项目教学的方式, 在实验部分引入基于Proteus和Keil技术虚拟实验的方式, 并逐步在教学中 实践应用, 在成绩考核及大赛能力培养等方面取得了一定的教学效果。

关键词: 实践性; 单片机与接口技术; 教学改革; 项目教学; 虚拟实验

前言

单片机技术是现代电子工程领域一门迅速发展的技术，是当前社会较为流行和热门的技术之一，其发 展极大地推动了电子工业的发展, 无论在教育界还是在产业界, 单片机技术的推广仍然是一个热点。“单 片机与接口技术” 课程属于一门多基础、多理论的实践性课程, 能够充分体现学生利用所学知识解决实际 工程问题的能力，通常在高校作为必修课开设。

目前, 几乎所有工科院校的自动化、机电一体化、通信、物联网等专业都开设了单片机与接口技术课 程, 并且在省级、国家级的技能大赛中都有以单片机为核心的赛项, 社会对单片机技术硬件设计工程师的 需求增长也相当迅速, 该课程的重要性也越来越明显。

\section{1 实践性单片机与接口技术课程改革与实施的具体意义}

\section{1 课程理论教学的现状}

传统的单片机教学基本都是以单片机的结构为主线, 先讲单片机的外部引脚、内部结构, 然后是指令 
编程, 定时器/计数器、中断概念、串口应用, 以及单片机存储器扩展和各种外围芯片的应用, 最后举一 些实例。教师完成理论知识教授, 学生需要记忆大量的指令、内部元件名称, 然后才能进行有限的实验验 证。

在多年的教学中, 学生普遍反映单片机课程太抽象、概念多、入门难、指令不易记等。学生感到枯燥 乏味, 学习难度很大, 教师的课堂教学效果也不够理想。为了改变目前教学现状, 需要对单片机的理论教 学模式进行改革。

\section{2 课程实践教学的现状}

单片机与接口技术课程实践性较强, 在教学过程中需要软硬件结合, 以理论教学为主, 实验教学为辅, 才能使学生更好更直观的理解所学知识, 达到学以致用的效果。一般的实验教学中需要配备较多硬件设备, 如电脑、仿真器、单片机实验箱、编程器等, 而且专门的单片机实验室还需要解决场地和实验员的问题, 对开课的高校提出了较多要求。

学生实验时也存在着不少问题. 单片机实验室由于存在着场地和时间等问题, 学生除了上课外, 平时 难得有机会实践; 个人配备单片机实验开发系统, 因成本较高, 很多学生无法承受; 同时一般单片机实验 箱由于是成品, 学生很难参与到其中的细节设计中去, 学生动手能力很难得到训练与提高。

单片机实验室建立成本高，实验设备不足，同时由于技术的不断更新，设备的不断老化，实验仪器也 会很快落后, 要解决这些问题需要不断的重建单片机实验室, 务必带来资金耗费严重等问题。

\section{3 基于项目教学和虚拟实验的实践性单片机与接口技术课程改革的意义}

结合学生、学校和课程的实际情况, 本文提出一种基于 “项目教学法”和 “基于Proteus及Kei1技术 的虚拟实验”的单片机课程教学改革方法。

在单片机课堂教学过程中, 教师应注重理论与实际应用结合, 运用案例教学, 激发学生的学习兴趣。 改革后采用了教、学、做一体的教学法, 学生学习以项目为中心, 有明确的任务, 能让学生围绕项目组织 已学知识和学习资源, 学习的主动性、积极性能得以发挥。项目教学法能充分调动学生的积极性、开拓同 学的思维、发挥同学的潜能、培养同学的个性、提高协调能力, 培养团队精神、增强竞争意识, 适应竞争激 烈的社会。

将Proteus和Keil仿真技术应用于单片机实践教学中, 又为解决实验条件有限等问题提供了一些思路。 通过仿真的直观性和可参与性以及生动有趣的真实感, 可以激发学生的学习兴趣, 提高教学效果, 尤其对 实验教学将产生积极影响。

本文的研究具有以下重要意义:

(1)、探索一种应用技术型、课程创新型的教学模式;

(2)、依据学生的学习过程和效果, 提出一种实验教学的新方法;

(3)、形象直观的教学模式可以有效提升学习兴趣、提高动手能力和创新能力的培养, 改善教学质量。

\section{2 改革内容}

为了贯彻高等院校 “应用为本、学以至用” 的办学理念, 在教学过程中要求学生做到 “会用、会看、 会做”。本课程的学习以80C51为内核的89系列单片机为使用背景, 以单片机C51为程序设计语言, 要求学 生掌握有关单片机硬件、软件及接口设计的基本概念、基本方法和基本技能, 针对不同的应用要求, 能够 
选择最适宜的单片机并能够设计、安装、调试接口电路、应用程序, 即能够设计出简单的应用系统。同时, 为学习后续课及在今后的工作中的应用打下必要的基础。在教学过程中我们做到理论教学授予学生基本理 论和分析方法; 实践教学贯穿于整个课程体系, 以巩固深化理论知识和培养学生实践动手能力为目的。

\section{1 理论授课方法的改革}

理工类课程教学中传统的教学模式大多按照知识体系逐点展开, 达到一定阶段后引入实践验证环节。 学习过程多为知识的理解记忆、逻辑推演。从学生的角度, 常常会有枯燥乏味的感觉。本部分主要进行教 学模式的改革。

在知识传授的同时, 注重学生学习兴趣的保持与知识应用能力的获得是当前素质教育须重视的问题。 为此本文提出一种理论实践一体化教学模式, 即通过 “项目+任务” 整合教学内容, 从按章节讲解改进为 按照项目讲解, 给出各项目功能和方案, 在分析方案的同时完成具体知识点的讲解。

将传统的单片机章节内容如单片机概论、单片机应用技术 C 语言基础、单片机开发工具使用、单片机 系统信息显示与输入功能、定时计数功能与中断技术、串行口与串行通信技术、单片机系统模拟量输入输 出技术、应用系统设计举例通过一些典型应用项目实例展开, 通过这些项目的设计、实现, 完成相关知识 内容的学习理解、能力锻炼。课程中设计的项目实例与传统按章节讲解内容对比如表 1 所示。

\section{表 1 课程内容的改革}

\begin{tabular}{|c|c|c|}
\hline 子项目名称 & 对应章节教学内容 & 课时 \\
\hline \multirow{5}{*}{$\begin{array}{l}\text { 子项目 1: } \\
\text { 基于单片机的 } \\
\text { 彩灯设计 }\end{array}$} & 1. 布置任务, 提出要求 & 12 \\
\hline & 2. 单片机最小系统 & \\
\hline & 3. I/0 引脚使用、发光二极管点亮方法。 & \\
\hline & $\begin{array}{l}\text { 4. 单片机 C 程序设计、Keil、Proteus、仿真器等工具的使用 } \\
\text { ( I )。 }\end{array}$ & \\
\hline & 5. 控制方案、点亮效果的分析讨论; 系统设计、调试、实现。 & \\
\hline \multirow{3}{*}{$\begin{array}{c}\text { 子项目 } 2: \\
\text { 基于单片机的 } \\
\text { 简易交通信号 } \\
\text { 灯模拟控制系 } \\
\text { 统设计 }\end{array}$} & 1. 布置任务, 提出要求 & 4 \\
\hline & $\begin{array}{l}\text { 2. 单片机 C 程序设计、Keil、Proteus、仿真器等工具的使用 } \\
\text { ( II ) ; 软件延时程序设计方法。 }\end{array}$ & \\
\hline & 3. 控制方案的分析讨论; 系统设计、调试、实现。 & \\
\hline \multirow{4}{*}{$\begin{array}{l}\text { 子项目 3: } \\
\text { 基于单片机的 } \\
\text { 计数器设计 }\end{array}$} & 1. 布置任务, 提出要求 & 8 \\
\hline & 2. 数码管原理、字型编码定义; LED 数码管静态和动态显示 & \\
\hline & 方法; LED 数码管接口电路设计; 数据拆分; 按键处理。 & \\
\hline & 3. 控制方案的分析讨论; 系统设计、调试、实现。 & \\
\hline 子项目 4: & 1. 布置任务, 提出要求 & 4 \\
\hline 基于单片机的 & 2. 字符型 LCD1602 引脚及命令字使用; 操作时序; 初始化过 & \\
\hline
\end{tabular}




\begin{tabular}{|c|c|c|}
\hline \multirow{2}{*}{$\begin{array}{c}\text { LCD1602 电子广 } \\
\text { 告牌设计 }\end{array}$} & \multicolumn{2}{|l|}{ 程 } \\
\hline & 3. 控制方案的分析讨论; 系统设计、调试、实现。 & \\
\hline \multirow{2}{*}{$\begin{array}{c}\text { 子项目 5: } \\
\text { 基于单片机的 }\end{array}$} & 1. 布置任务, 提出要求 & 12 \\
\hline & 2. 定时计数器使用; 定时问题和计数问题的解决方法; 相关 & \\
\hline \multirow[t]{2}{*}{ 简易时钟设计 } & SFR 使用; 中断函数与中断服务程序设计; 按键处理。 & \\
\hline & 3. 方案的分析讨论; 系统设计、调试、实现。 & \\
\hline \multirow{4}{*}{$\begin{array}{c}\text { 子项目 6: } \\
\text { 基于单片机的 } \\
\text { 点对点通信系 } \\
\text { 统设计 }\end{array}$} & 1. 布置任务, 提出要求 & 6 \\
\hline & 2. 串行通信基本知识; 串行口结构; 特殊功能寄存器 SCON、 & \\
\hline & PCON 的作用及设置; 串行口的工作方式。 & \\
\hline & 3. 方案的分析讨论; 系统设计、调试、实现。 & \\
\hline \multirow{4}{*}{$\begin{array}{c}\text { 子项目 } 7: \\
\text { 基于单片机的 } \\
\text { 简易双精度数 } \\
\text { 字电压表设计 }\end{array}$} & 1. 布置任务, 提出要求 & 8 \\
\hline & 2. 模拟量转 ADC0809、0804 使用及与单片机的接口电路与程 & \\
\hline & 序设计; 显示接口电路与程序设计。 & \\
\hline & 3. 方案的分析讨论; 系统设计、调试、实现。 & \\
\hline \multirow{5}{*}{$\begin{array}{c}\text { 子项目 8: } \\
\text { 基于单片机的 } \\
\text { 简易波形发生 } \\
\text { 器设计 }\end{array}$} & 1. 布置任务, 提出要求 & 6 \\
\hline & 2. 数字量的转换; 常见波形的产生; DAC0832 与单片机的接口 & \\
\hline & 电路与程序设计方法。 & \\
\hline & 3. 方案的分析讨论; 系统设计、调试、实现。 & \\
\hline & 课时总计 & 60 \\
\hline
\end{tabular}

\section{2 实验授课方法的改革}

从以上教学内容的设置可以看出, 实验在单片机课程中占据举足轻重的地位, 紧密配合理论教学的实 验是帮助学生接受、理解、掌握单片机工作原理和开发技巧的重要环节。所以单片机课程教学过程中必须 开设足够的实验学时来辅助理论教学的实施。

随着现代科技的发展, 利用计算机软件的仿真技术, 可以充分地仿真实际的工程问题。仿真能节约设 计成本, 大大增强了实验的便利性。Proteus 是一款嵌入式系统软硬件设计仿真平台, 具有模拟电路仿真、 数字电路仿真、单片机及其外围电路组成的系统仿真等。它的独特之处是能够在线、实时仿真多种类型的 单片机, 实现硬件电路的交互仿真, 功能极其强大。自带有 ASM、PIC、AVR 汇编器等, 也可与第三方软件 Keil 结合使用。用单片机原理及接口技术的理论知识与 Proteus、Keil 软件结合, 设计出以 MCS-51 单片 机为核心的系列虚拟实验, 应用到单片机课程的教学中, 可以解决单片机课堂教学无法及时实验等问题, 可以增强学生学习的直观性和主动性, 可以辅助学生达到对单片机应用系统设计的深入理解。

本部分介绍一种将仿真软件 Proteus 和 Keil 引入到单片机课程的教学中, 进而解决实验室紧张、学 生课后无法自主实验等问题的一种新方法。单片机课程教学中引入基于 Proteus 和 Keil 软件的虚拟实验 后, 可以节约实验室建设的人力、物力和财力成本, 还可以增加学生课后练习的机会, 大大提升教学质量。 如图 1 所示为在教学中引入 Proteus 和 Keil 软件后学生可以自主完成的单片机实验效果。 


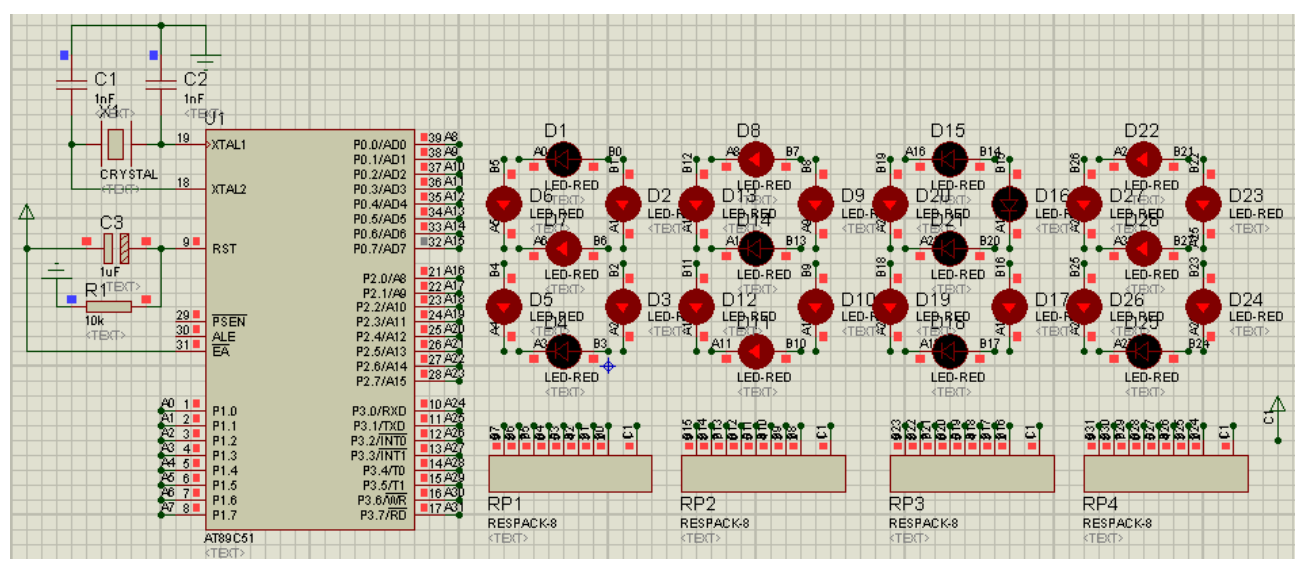

图 1 基于 Proteus 和 $\mathrm{Keil}$ 的虚拟实验效果

\section{3 考核方式的改革}

由于单片机课程实践性较强的特点决定了教学过程采用理论实践一体化的项目教学模式, 因此通过对 本课程各环节内容的学习、实践, 应强调使学生掌握单片机应用系统的初步设计方法、编程能力和应用分 析能力, 掌握正确安装和调试单片机系统的技能, 课程的最终目标是教会学生一种方法。所以本课程的考 核方式也由原来的闭卷笔试改革为开卷机试的方式，由应试考核变为应用能力的考核。经过多年的教学实 践证明，改革后的考核方式更能充分体现学生学习后获得的成果。

考核方式具体分配如图 2 所示。

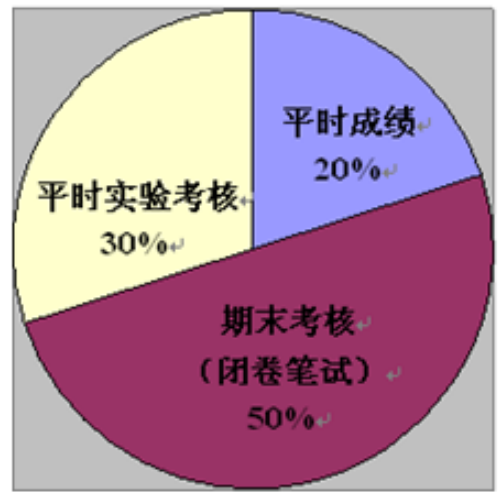

改革前成绩构成

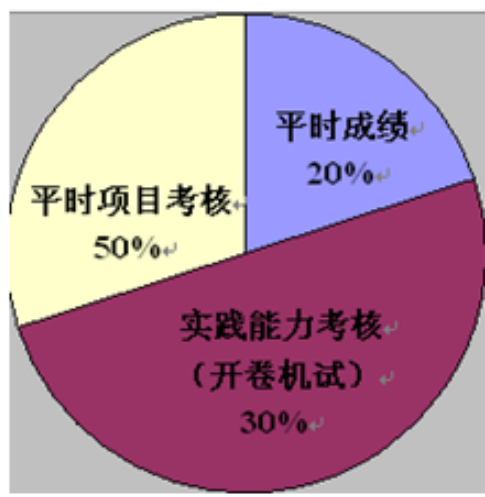

改革后成绩构成

图 2 考核方式及比例的改革

\section{3 本项目的特色与创新}

\section{1 基于项目驱动法的理实一体化教学设计}

运用 “基于项目驱动法的理实一体化” 的方式突出理论与实践的结合，采用过程性考核与开卷考试代 替闭卷的考核方法, 多方位推行教学改革, 实践证明, 改革后的教学模式具有开放性和可拓展性, 能提高 学生学习兴趣与动手能力, 有着良好的教学效果, 值得推广。

\section{2 基于 Proteus 和 Kei1 的虚拟实验室设计}

Proteus 仿真软件能够提高开发效率，降低开发成本，缩短开发周期，用 Proteus 软件虚拟单片机， 具有系统资源丰富、硬件投入少、形象直观等优点，能更好地培养学生解决实际工程问题的能力。

利用 Proteus 和 Keil 软件进行单片机系统的设计与仿真, 结合教学实际情况设计相关的虚拟实验, 
可以大大提高教学的直观性和形象性, 提高学生的理解程度和学习兴趣, 加深学生对单片机原理的认识, 锻炼学生进行软硬件综合开发的能力, 进而提高教学质量。

教学中引入基于 Proteus 和 Keil 软件的虚拟实验后, 可以节约实验室建设的人力、物力和财力成本, 还可以增加学生课后练习的机会, 大大提升教学质量。

\section{3 与时俱进, 紧密联系大赛, 充分调动学生学习积极性}

工业控制、智能家居、物联网通信等行业单片机应用无处不在，历年来省级国家级的技能大赛及大学 生电子设计竞赛中也都会有关于单片机类的题目, 而所采用的基础知识就是本门课程讲解的内容, 所以无 论是在项目引入时还是实验设计时, 都可以选用真实项目或者大赛内容, 学生学习兴趣会更加浓厚, 也为 大赛打下基础。

\section{4 结论}

经过四年多的教学实践探索，基于项目教学和虚拟实验的实践性单片机与接口技术课程改革已收益显 著。一线教师的教育理论水平和教改能力获得明显提升, 先后发表了若干篇高水平论文, 并成功申请完成 了多项教改立项。学生的考试成绩也较改革前有大大提高, 平均成绩达到了 80 分以上。另一方面一些学 生先后在高水平科技竞赛活动中多处获奖，例如辽宁省高职院校职业技能大赛分别有一、二、等奖的好成 绩。

\section{5 致谢}

感谢辽宁广播电视大学（辽宁装备制造职业技术学院）2016YYYJ-1 基金。

\section{Acknowledgement}

Thanks to Liaoning Radio and Television University (Liaoning Equipment Manufacturing Vocational and Technical College) 2016YYYJ-1 Fund.

\section{参考文献：}

[1] 郭杰. 职业学校单片机教学改革的探索与思考 [J]．教师，2013(11)：101-102.

[2] 陈向奎，李元臣. 单片机教学改革的思考与探索 $[\mathrm{J}$ ．洛阳师范学院学报，2012，31 (5)：84-86.

[3] 郭海运，李志丞. 浅谈单片机教学改革 $[J]$. 电子制作，2013 (7)：168-168.

[4] 胡敬朋, 王聪. 关于单片机教学改革的几点意见 [J]。电气电子教学学报, 2009，31 (5)：93-96.

[5] 肖忠, 彭凌西. 理论实践一体化教学模式在单片机课程教学中的探讨 [J]. 黑龙江科技信息, 2016, (32)：139-140.

[6] 张琳琳. Proteus 仿真软件在高职单片机课程改革中的应用 [J]. 河北软件职业技术学院学报, 2016, (04)：60-64.

[7］向兵，乔之勇．单片机应用技术课程的项目化教学改革与实践 [J]．科技创新导报, 2016, (28)：158-159.

[8] 关志艳. Proteus 导向项目扩展的单片机实验建设 [J]。仪表技术, 2016, (12)：10-13+18.

\section{References:}

[1] Guo Jie. Exploration and Reflection on Reform of Single-Chip Computer Teaching in Vocational Schools [J].Teacher, 2013 (11):101-102.

[2] Chen Xiangkui, Li Yuanchen. Thinking and Exploration of Teaching Reform in Single Chip Computer [J].Journal of Luoyang Normal University, 2012, 31(5):84-86.

[3] Guo Haiyun, Li Zhicheng. On Single - Chip computer Teaching Reform [J].Practical Electronics, 2013(7):168-168.

[4] Hu Jingpeng, Wang Cong. Several Comments on the Teaching Reform of MCU [J].Journal of Electrical \& Electronic Education, 2009, 31(5):93-96. 
[5] Xiao Zhong, Peng Lingxi. Discussion on Integration of Theory and Practice of Teaching Mode in Single Chip Computer Course Teaching [J].Heilongjiang Science and Technology Information Magazine,2016,(32):139-140.

[6] Zhang Linlin. Application of Proteus Simulation Software in Course Reform of Single-Chip Microcomputer in Higher Vocational Education [J].Journal of Hebei Software Institute,2016,(04):60-64.

[7] Xiang Bing, Qiao Zhiyong. Reform and Practice of Project Teaching in Applications Course of Single Chip Microcomputer [J].Science and Technology Innovation Herald, 2016, (28):158-159.

[8] Guan Zhiyan. Experiment Construction of Single Chip Microcomputer in Proteus - Oriented Project [J].Instrumentation Technology, 2016,(12):10-13+18. 